\title{
The Effectiveness of Using Internet in TEFL Learning
}

\author{
Amel Jassim Khalaf \\ English Language Unit, College of Arts, Kuwait University, Kuwait
}

\begin{abstract}
This study aimed at investigating the effectiveness of internet in learning English through testing TEFL courses outcomes. The main data was collected by both an interview with the TEFL tutors and a questionnaire with the students taking TEFL courses in Kuwait. The sample of this study included 5 TEFL trainers and 150 students in Kuwait. The questionnaire and interview contained four main sections (advantages of using the internet, disadvantages of using the internet, most effective internet-related tools that are used in TEFL courses and the recommendations that can be followed to enhance the quality of the internet in TEFL courses). The results revealed that using internet has a positive impact on the effectiveness of learning English and TEFL courses, it also showed that the speed, availability, affordability, easiness and other factors are some of the advantages of the internet. However, cheating, lack of communication, technical problems and unreliable information are some of the disadvantages of using the internet. Moreover, this study concluded that YouTube is the most effective internet tool that is used to teach TEFL and EduBuncee is the weakest one. This study recommended improving the role of social media in TEFL courses by creating more interactive methods.
\end{abstract}

Index Terms - TEFL, learning English, Kuwait, internet learning

\section{INTRODUCTION}

With the development and spread of the English language across the world, it is applied as a second language within many countries; moreover, it is the first language to other countries. English have a great prestige within some countries (Honna, 2005; Crystal, 2012). Now English status and role is greater than ever like evidenced through its position like an important subject of the medium of curriculum and instruction. Since the English learners' number is growing, diverse education techniques have been applied to assess the teaching process effectiveness. Employ of accurate materials within the TV form, films and radio has been presented for an extended time. Actually, these technologies have verified successfully within substituting the traditional teaching (Shyamlee \& Phil, 2012).

The novel era assigns novel duties and challenges of the modern teacher. The English teaching tradition has been radically changed among the technology remarkable entry. Technology is providing a lot of options since making teaching interesting in addition to making teaching further productive for developments. Technology is one of the mainly important drivers of equally linguistic and social change. According to Graddol (1997), technology is in the center of the globalization process; in a shape that affect culture and education work. English language use has rapidly increased afterward 1960. Now, the status and role of English relies on the fact that it is the social context language, political language, sociocultural, business, education, industries, media, library, communication across borders, and vital subject in language and curriculum of communicating education. In addition, it is a critical determinant for university entrance in addition to processing well-remunerated jobs within the commercial part (Patel, 2013). While there are increasingly English learners, diverse teaching techniques have been applied to test the teaching process effectiveness. One method engages multimedia within ELT to create English circumstances. This assists students to learn and be involved consistent with their needs, it has been experienced effectively as well as is extensively acknowledged to English teaching within contemporary world (Pun, 2014).

Technology is utilized for the modern styles upliftment; where it satisfies equally auditory and visual students' senses (Erben, Ban \& Castaneda, 2008). With the development and spread of English internationally, it has been used as well as learned by increasingly speakers. Consistent with David Graddol, English is the language at the technological and scientific development leading edge, innovative thinking in management and economies, innovative entertainment genre and literatures (Graddol, 1997, p. 2). This study aims at investigating about the effectiveness of using internet in TEFL learning.

\section{Study questions}

The following are the main questions that this study is trying to answer:

1. What is the effect of using internet on teaching TEFL

2. What are the main advantages and disadvantages of using internet on teaching TEFL

3. What is the most effective internet-based way in teaching TEFL?

Hypothesis 
H1: using the internet has a positive impact on the effectiveness of TEFL courses outcomes

\section{LITERATURE REVIEW}

\section{Technology Use in English Teaching}

Since the English use has amplified in acceptance, the requirement for practiced educators to educate students within the language has increased. It is accurate that here are teachers who utilize the technology of 'cutting edge', but the greater part of educators immobile teach in the old way. Not any of these old ways are terrible or destructive for the students (Parvin \& Salam, 2015; Raiskinmäki, 2017). Still, there are several opportunities in front of students to increase confidence practice and outspread themselves, particularly for ESL students who study the language to purposes other than fun. To them for keeping pace with ELT in addition to gain more confidence they must pace into the multimedia technology domain (Motterram, 2013).

\section{The Impact of Using Educational Websites on learning}

The significance of the Internet within education is a good recognized fact. It gives access to many information resources that are difficult for being obtained through additional traditional means (Higgins, Xiao \& Katsipataki, 2012). The incessant improvements within Internet technologies are giving novel learning environments, which attract learners as well as motivate them for learning. The use of the internet within higher education is rising and has turn into a significant topic in a lot of educational researches and journals. It is playing a significant role in improving and facilitating the English learning process (Ta'amneh, 2014; Robová, J. (2013; Wong, 2013).

Modern Web-based learning gives the means to change the thinking way in that the learning resources are carried to learners. Consistent with Medina (2002) by web learning and multimedia resources can make education extra widely available, improve the process of learning, improve the learning environment, and create cost efficient solutions to the knowledge dissemination.

Many educational websites have good features for example narrative, interactive examples, video, written text, and animation. These websites are intended to give students among a "self-help" learning source to match traditional textbook (Arsham, 2002). They create a wonderful environment to improve and enrich educational process during interactive hypertext, communication and collaboration in addition to dynamic content (Taylor, 2002).

Consistent with Karisiddappa (2002), the sources of online media have been observational as information valuable sources, which can help learners in raising their capacity to social interaction. They are observed to promote creativity and investigation through the interaction of different knowledge forms such as graphics, text, photos, multimedia, music, video, animation, sound, etc.

Instructors ought to use these websites for enhancing learners' communicative abilities so as to express themselves within the target language in addition to give learners the chances to interact among others and efficiently experience negotiation through classroom instruction (Sawadogo, 2004). Concerning learners in meaningful and authentic interactions with learners, universal using the internet can motivate learners for keeping learning and hold learners for becoming more willing and responsible to engage within their possess learning, that is defined like learner autonomy (Toyoda, 2001).

\section{The TEFL Concept}

Following to mentioning the English importance in society as well as the corporate world, the English classes take action as a medium for which obtaining English skills are probable. TEFL claims for simply being the improved and new modern catering version to those requests. EFL is learned either for passing exams as an essential part for one's education, or to career progression as working to a business or organization with an international center. EFL can be division of the curriculum of the state school in countries wherever English has no particular status; it also may be complemented by lessons salaried for privately. However, TEFL is expected at those wanting for teaching English to clients in addition to prospective topics who desire for learning English as a $2^{\text {nd }}$ or foreign language. One more EFL vantage point is to collect a sight of the techniques as well as teachings thereof, this is identified as TEFL. The TEFL course for EFL trainers contains (as collected of TEFL's lesson curriculum) of 12 chapters changeable from teacher-student association, class management to lesson planning and teaching grammar (Irmscher, 2011).

The course just offers a 6 month window for completing the program moreover to reach the total of 150 hours. Consistent with Teflonline, the permitted period is enough to acquire every necessary piece of information wanted to can teach English like a foreign language for students whose mother language is not English. At the end of every chapter, accompanied among video tutorials, the module exams are in use. The mark for passing each module is 70\%. Every TEFL member course has a personal teacher, which assists him/her all through the whole course, for aiding in every uncertainty, or for common help. This is to make sure that potential EFL teachers have every necessary materials and aids to their discarding. The Researcher has finished this TEFL program through Bridge TEFL in addition to have successfully achieved a TEFL certificate for teaching English like a foreign language. Personal insight can be given on the standard and duration of this course. The Researcher is of view that the main components of the English learning for example, vocabulary, grammar, sentence structure, phonology, and concord, productive/receptive language skills are methodically explained within the TEFL course. Further factors each EFL 
teacher ought to keep in mind are, inter alia classroom management, the role of the student and teacher, lesson planning, error correction, cultural awareness, how to supervise teaching aids and group exercises, support the student during learning. The Researcher is also of view, taking into account the sum of exercises and literature, which have to be finished; the TEFL course presents an ample quantity of time for every course modules for being completed (Irmscher, 2011).

\section{TEFL Strategies and Methods}

The first EFL implement, Metacognition is defined by Flavell (1979) as:

"...the experiences and knowledge we have about our own cognitive processes"

(Schwartz and Perfect, 2002, p. 1).

Metacognition is thinking on thinking, a powerful instrument for effective learning and teaching; moreover, it is an integral element of the EFL teaching. Through linking metacognition to his/her teaching plans, the EFL teacher can plan and prepare to an every class. This is completed by selecting in addition to using applicable and specific learning strategies. Then the teacher is able to orchestrate different techniques, monitor the strategy utilize, then finally assess those strategies within the lesson plan.

Many educators believe adults and children of non-English-speaking environments will study English best throughout structured immersion, wherever they have EFL or ESL classes in addition to content-based instruction within English (McLaughlin, 1992).

Teachers recognize that subjects learn in diverse ways; the knowledge within the classroom verifies this each day. Additionally, extensive research and well-accepted theories document and illustrate learning differences. Nearly all educators can converse about learning divergences, whether through the name of psychological type, learning styles, multiple intelligences, or cognitive styles. Learners get their own character approach, interests and talents to the learning condition. It is a very important position of EFL to nurture as well as enhance these exceptional learning capabilities of the subjects to secure victorious language acquisition (McLaughlin, 1992).

The EFL teacher plans and prepares for every class by notifying the subjects on the aims as well as the objective to the exercises, expected outcomes to the class, plus the reason for group activities and pair work etcetera. Then the lecturer leaves on to use and selects learning strategies through teaching the subjects diverse learning methods; for instance, showing them memo-taking strategy, outline practicing in addition to chart forms. The EFL teacher monitors plan use by talking about among the subjects that note taking plan they prefer as well as what and why they find difficult about the additional methods. The teacher of EFL orchestrates different strategies through applying two strategies addicted to the lesson. Those strategies are intended to complement every other and develop the learning procedure.

For instance, in vocabulary advance, BridgeTEFL, consider that the multiple strategies application for the vocabulary acquisition is helpful in increasing the speed of the word learning and rising the time length for keeping a word. Whether a learner performs the writing strategy all novel vocabulary down, defining it, categorizing it, reading the word repeatedly, using it within a sentence, hearing it, associating several imagery among the word, and orally employing it within context, the learner can benefit extra a learner who experienced just one of those strategies.

Lastly, by assisting strategy use moreover learning, the EFL teachers repeat the learners for evaluating their strategies to learn. Quizzes are given to aid in evaluation, which are stranded on content which was learned through a conscious strategy, or during several diverse learning strategies, as well as through letting subjects believe the different strategies outcome in addition to what works greatest for them.

The EFL teacher as a result, by practicing and teaching metacognitive skills within the classroom, is able to allow the subjects for achieving higher learning through supplying them with apparatus to make aware decisions on their learning procedure.

Little distinct characteristics of the EFL teachers are to the present novel language within context through roleplay or visual situations. EFL teachers not at all ask questions except they have qualified the subjects how to respond those questions as well as they learn for anticipating problems. In addition, EFL teachers praise subjects as they get questions correct, but they do not support them. In addition, the EFL teacher not at all abandons a subject when topics do not recognize, instead they go back to the work, analysis it, and incorporate it to additional lessons in anticipation of the subjects understand.

An additional TEFL characteristic concerning grammar is the employ of the exercise drills.

A distinctive TEFL exercise drill for instance repetition, would appear as the following:

Teacher: "He's sleeping."

Subjects: "He's sleeping."

Teacher: "She's sleeping."

Subjects: "She's sleeping."

Teacher: "Great!"

Then the teacher of EFL can continue to satisfied through the subjects' pronunciation and understanding. Another step within this exercise is to insert more differentiation, through adding a drill among 'wh' questions similar to "with", "why","who". This can be used as well as the yes/no questions. The teacher keeps on the exercise also asks 
with a sequence of pictures revealed for the subjects for eliciting the responses which the teacher needs: "Is he sleeping?"

Subjects: "Yes, he's sleeping."

Teacher: "Is he sleeping?"

Subjects: "No, he isn't sleeping."

Teacher: "What's he doing?"

Subjects: "He's reading."

Teacher: "That's right"

Teacher: "What's she doing?"

Subjects: "She's reading."

Teacher: "Very good!"

\section{METHODOLOGY}

In this study, a mixed methodology of both qualitative and quantitative methods was used. At first, the primary data was collected by making interviews with 5 TEFL trainers where the questions were focusing on the following aspects:

- How are students influenced by using Internet-based ways of teaching TEFL

- the main advantages of using Internet-based way to teach TEFL

- the main disadvantages of using Internet-based way of teaching TEFL

- the most effective Internet-based way to teach TEFL

- Recommendations to increase the effectiveness of TEFL courses

Moreover, a questionnaire was distributed on 150 students in Kuwait who are taking or took a TEFL course while the questionnaire concentrated on the following aspects:

- Using the internet in TEFL courses

- Advantages of using the Internet in TEFL courses

- Disadvantages of using the Internet in TEFL courses

- Internet-related tools

\section{RESULTS}

\section{Questionnaire results}

Total of (23) hypothesized items to denote ten scales were established to be used in this study. The scales were established depending on a review for the related studies and literature that offers evidence of the validity of the content. This parts presents the method of selection of items, and the reliability and validity evaluation of the measurement scales. Moreover, the items of each scale reliability were measured by Cronbach's coefficient alpha depending on the scales internal consistency. The Acceptable and unacceptable levels of the Cronbach's Alpha coefficient as presented in next table.

TABLE (1)

ACCEPTABLE AND UNACCEPTABLE LEVELS OF THE CRONBACHS’ ALPHA COEFFICIENT

\begin{tabular}{|l|l|}
\hline Alpha coefficient & implied reliability \\
\hline Below .60 & Unacceptable \\
between .60 and .65 & Undesirable \\
between .65 and .70 & minimally acceptable \\
between .70 and .80 & Respectable \\
between .80 and .90 & very good \\
\hline
\end{tabular}

Beside that in Nunnally's (1978) guideline, scale reliability of 0.70 and above is preferred. Nunnally (1978) also proposes that items that are less than 0.30 values to total correlation can be deleted in order to develop the scale reliability. The results of this study shows that the value of Cronbach's coefficient alpha for scales are different in the values according to analysis data. In this study, we computed Cronbach's coefficient alpha for the scales before data screen, after data screen,

TABLE (2):

THE STABILITY OF THE INSTRUMENT (CRONBACH'S ALPHA) FOR THE VARIABLES OF THE STUDY

\begin{tabular}{|l|l|}
\hline & Cronbach's alpha \\
\hline Using the internet in TEFL courses & 0.91 \\
\hline Advantages of using the Internet in TEFL courses & 0.88 \\
\hline Disadvantages of using the Internet in TEFL courses & 0.91 \\
\hline Internet-related tools & 0.93 \\
\hline Total & 0.94 \\
\hline
\end{tabular}

All alpha values were acceptable. 
Respondents' Characteristics. The profile of the respondents with to Gender, Age, Nationality, Education shown in Table (3).

TABLE 3:

FREQUENCY AND PERCENTAGE FOR DEMOGRAPHIC INFORMATION

\begin{tabular}{|l|l|l|l|}
\hline \multirow{4}{*}{ Gender: } & & Frequency & Percent \\
\hline \multirow{4}{*}{ Age category: } & Male & 66 & 44.0 \\
\cline { 2 - 4 } & Female & 84 & 56.0 \\
\cline { 2 - 4 } & Total & 150 & 100.0 \\
\cline { 2 - 4 } & $17-19$ years & 61 & 40.7 \\
\cline { 2 - 4 } & 20-25 years & 72 & 48.0 \\
\cline { 2 - 4 } & More than 25 & 17 & 11.3 \\
\cline { 2 - 4 } & Total & 150 & 100.0 \\
\hline \multirow{5}{*}{ Edionality } & Kuwaiti & 142 & 94.7 \\
\cline { 2 - 4 } & Bahrain & 4 & 2.7 \\
\cline { 2 - 4 } & Saudi Arabia & 4 & 2.7 \\
\cline { 2 - 4 } & Total & 150 & 100.0 \\
\hline & Education & 9 & 6.0 \\
\cline { 2 - 4 } & Bachelor & 6 & 4.0 \\
\cline { 2 - 4 } & High school & 135 & 90.0 \\
\cline { 2 - 4 } & not educated & - & - \\
\cline { 2 - 4 } & Total & 150 & 100.0 \\
\hline
\end{tabular}

Table 3 show that:

1. The majority of the respondents within the gender group are $(44.0 \%)$ per cent is male and are $(56.0 \%)$ female.

2. With regard to the age, most of the respondents (48.0\%) per cent are in the age group of (20-25 years), (11.3\%) per cent are More than (More than 25).

3. With regard to the Nationality, most of the respondents (94.7\%) per cent are Kuwaiti, (2.7\%) per Bahrain, Saudi Arabia.

4. With regard to the Education, most of the respondents $(90.0 \%)$ per cent are in the(High school), $(4.0 \%)$ per cent are (Bachelor).

This part, including as a result of the study depends on the descriptive statistics:

Results of the first question: What is the effect of using internet on teaching TEFL?

table (4) shows some descriptive results for the research Using the internet in TEFL courses

The table shows mean and standard deviation for the research variables of Using the internet in TEFL courses.

TABLE 4

MEANS AND STANDARD DEVIATIONS FOR THE APPROVAL OF THE RESPONDENTS ON THE LEVEL OF USING THE INTERNET IN TEFL COURSES IN A DESCENDING ORDER

\begin{tabular}{|l|l|l|l|l|l|}
\hline Rank & No & & Mean & Std. Deviation & Degree \\
\hline 1 & 1 & Using the internet has helped my learning journey. & 4.44 & 0.64 & High \\
\hline 2 & 3 & $\begin{array}{l}\text { Using interactive tools such as YouTube, online dictionary, etc. have eased the } \\
\text { learning process }\end{array}$ & 4.22 & 0.78 \\
\hline 3 & 2 & $\begin{array}{l}\text { I gained more vocabulary than what was planned in my course after using the } \\
\text { Internet }\end{array}$ & 4.20 & 0.70 & High \\
\hline 4 & 5 & $\begin{array}{l}\text { The traditional learning ways have a lot of limits that can be avoided through } \\
\text { using the Internet }\end{array}$ & 3.77 & 1.05 \\
\hline 5 & 4 & The burden on the teacher is now less since using the Internet & 3.67 & 1.07 & High \\
\hline \multicolumn{2}{|l|}{} & 4.06 & 0.48 \\
\hline
\end{tabular}

Table 4 shows that the arithmetic means for the sample's approval for the level of the Using the internet in TEFL courses with other team members ranged from (3.67-4.44) and the highest was item No. (1), which reads: "Using the internet has helped my learning journey" while the lowest was item (4), which reads: The burden on the teacher is now less since using the Internet." the arithmetic mean for the field as a whole was (4.06) with a High degree.

Results of the second question: What are the main advantages and disadvantages of using internet on teaching TEFL?

Table (5) shows some descriptive results for Advantages of using the Internet in TEFL courses. The table shows mean and standard deviation for the research variables of Advantages of using the Internet in TEFL courses. 
TABLE 5

MEANS AND STANDARD DEVIATIONS FOR THE APPROVAL OF THE RESPONDENTS ON THE LEVEL OF ADVANTAGES OF USING THE INTERNET IN TEFL COURSES IN A DESCENDING ORDER

\begin{tabular}{|c|c|c|c|c|c|}
\hline Rank & No & & Mean & Std. Deviation & Degree \\
\hline 1 & 1 & There is always an explanation for my mistakes which enhances my understanding & 3.89 & 0.84 & High \\
\hline 2 & 6 & I can ask experts from all around the world for explanations & 3.85 & 0.85 & High \\
\hline 3 & 2 & I get immediate feedback for my work & 3.77 & 1.06 & High \\
\hline 4 & 3 & I can have a break whenever I want & 3.71 & 0.97 & High \\
\hline 5 & 5 & I have a full-time available teacher using online resources & 3.65 & 0.94 & Medium \\
\hline 6 & 4 & There is no embarrassment in asking questions or making mistakes & 3.63 & 1.10 & Medium \\
\hline 7 & 7 & I can afford learning English in this way & 3.62 & 0.95 & Medium \\
\hline 8 & 8 & There aren't any complicated steps that need to be followed to learn English online & 3.53 & 0.96 & Medium \\
\hline \multicolumn{3}{|l|}{ Total } & 3.71 & 0.49 & High \\
\hline
\end{tabular}

Table 5 shows that the means for the sample's approval for the level of the advantages of using the Internet in TEFL courses ranged from (2.53-3.89) and the highest was item No. (1), which reads: "There is always an explanation for my mistakes which enhances my understanding" while the lowest was item (8), which reads: "There aren't any complicated steps that need to be followed to learn English online" the arithmetic mean for the field as a whole was (3.71) with a High degree.

Table (6) shows some descriptive results for Disadvantages of using the Internet in TEFL courses. The table shows mean and standard deviation for the research variables of Disadvantages of using the Internet in TEFL courses.

TABLE 6

MEANS AND STANDARD DEVIATIONS FOR THE APPROVAL OF THE ESPONDENTS ON THE LEVEL OF DISADVANTAGES OF USING THE INTERNET IN TEFL COURSES IN A DESCENDING ORDER

\begin{tabular}{|l|l|l|l|l|l|}
\hline Rank & No & & Mean & Std. Deviation & Degree \\
\hline 1 & 1 & There is a lack of communication between my teacher and me & 3.79 & 1.08 & High \\
\hline 2 & 2 & Technical interruptions occur often during my learning sessions & 3.59 & 0.83 & Medium \\
\hline 3 & 6 & I feel that I am lost with no guidance & 3.51 & 1.07 & Medium \\
\hline 4 & 3 & The computer cannot deal with my unexpected questions & 3.47 & 1.05 & Medium \\
\hline \multicolumn{2}{|l|}{ Total } & 3.59 & 0.71 & Medium \\
\hline
\end{tabular}

Table 5 shows that the arithmetic means for the sample's approval for the level of the Disadvantages of using the Internet in TEFL courses ranged from (3.47-3.79) and the highest was item No. (1), which reads: "There is a lack of communication between my teacher and me" while the lowest was item (3), which reads: "The computer cannot deal with my unexpected questions" the arithmetic mean for the field as a whole was (3.59) with a medium degree.

Results of the Third question: What is the most effective internet-based way in teaching TEFL?

Table (7) shows some descriptive results for Internet-related tools. The table shows mean and standard deviation for the research variables of Internet-related tools.

TABLE 7

ARITHMETIC MEANS AND STANDARD DEVIATIONS FOR THE APPROVAL OF THE MEMBERS OF THE STUDY SAMPLE ON THE LEVEL OF INTERNETRELATED TOOLS IN A DESCENDING ORDER

\begin{tabular}{|l|l|l|l|l|c|}
\hline Rank & No & & Mean & Std. Deviation & Degree \\
\hline 1 & 3 & I use YouTube tools in TEFL learning & 3.56 & 1.08 & Medium \\
\hline 2 & 6 & I use English grammar online in TEFL learning & 3.49 & 1.14 & Medium \\
\hline 3 & 5 & I use Cambridge dictionaries online in TEFL learning & 3.33 & 1.11 & Medium \\
\hline 4 & 4 & I use ESL conversation online in TEFL learning & 3.18 & 1.00 & Medium \\
\hline 5 & 1 & I use Web 2.0 tools in TEFL learning & 3.04 & 1.09 & Medium \\
\hline 6 & 2 & I use the EduBuncee tool in TEFL learning & 2.99 & 1.03 & Medium \\
\hline \multicolumn{2}{|l|}{ Total } & 3.27 & 0.80 & Medium \\
\hline
\end{tabular}

Table 7 shows that the arithmetic means for the sample's approval for the level of the Internet-related tools ranged from (2.99-2.56) and the highest was item No. (3), which reads: "I use YouTube tools in TEFL learning" while the lowest was item (2), which reads: "I use the EduBuncee tool in TEFL learning" the arithmetic mean for the field as a whole was (3.27) with a medium degree.

\section{Testing the study hypotheses}

Hypothesis testing in the model were conducted depending on 3 measures, the Coefficient of Determination (R2), the significance of Correlation Coefficients (R), and the Multiple Regression (Beta).

Possible correlations ranged from ( +1 to -1$)$. Generally, as a rule of thumb, the values of $r$ that are 0 to .2 are considered weak while the values from .3 to .6 are considered moderate then, the values from .7 to 1 are considered strong (Brace et.al, 2000). The coefficient of determination $\left(\mathrm{R}^{2}\right)$ is useful since it offers the variance proportion of one variable, which is predictable out from the other variable. This measure allows to define how certain one can be in building predictions from a certain graph/model. The Multiple Regression determined by Beta that is a measure for how each set of predictor variables strongly effect the criterion variable. Multiple regressions use can test theories about precisely that variables set is affecting our behavior. Generally, the Correlation Coefficients (R) can 
measure the relation between two variables only but the Multiple Regression, Beta, can measure the relation between a set of variables with one variable. The Coefficient of Determination $\left(\mathrm{R}^{2}\right)$ shows the linearity between many variables. In this study, we test $r$ through Pearson Correlation Coefficients determined for variables pairs in order to test the correlation coefficients significance. Beta is determined through applying the linear regression test.

H01: using the internet has a positive impact on the effectiveness of TEFL courses outcomes:

\section{TABLE (8):}

THE RESULTS OF THE APPLICATION OF THE REGRESSION USING THE INTERNET HAS A POSITIVE IMPACT ON THE EFFECTIVENESS OF TEFL COURSES

\begin{tabular}{|c|c|c|c|c|c|c|c|}
\hline \multicolumn{8}{|c|}{ OUTCOMES } \\
\hline & B & $\mathbf{T}$ & Sig. & $\mathbf{R}$ & R2 & $\mathbf{F}$ & Sig. \\
\hline $\begin{array}{l}\text { using the internet has a positive impact on the } \\
\text { effectiveness of TEFL courses outcomes }\end{array}$ & 0.36 & 4.67 & 0.00 & 0.36 & 0.13 & 21.80 & 0.00 \\
\hline
\end{tabular}

According to the results of the above table (8) that there is a relationship statistically significant at the significance level $(0.05=\alpha)$ between using the internet has a positive impact on the effectiveness of TEFL courses outcomes, as the value of the correlation coefficient (R) of (0.39), a value statistically significant and indicate the degree of correlation statistically significant between the independent variables and the dependent variable, and the value of (R-square) (0.13), a statistically significant value, and the value of the test (F) (21.80) in terms of the statistical (0.00), which value statistically significant at the significance level $(0.05=\alpha)$, therefore, accept the alternative hypothesis.

\section{Interview results}

According to the TEFL teachers, one of the main advantages of Internet-based ways is to open the students to wider range of options and opportunities while the loss of communication was the main disadvantage of Internetbased ways. You tube was classified as the most effective and common internet-based way to teach TEFL. Incorporating the social media and strengthen the role of discussion seminars were the main recommendations that were proposed by most of the teachers.

\section{DISCUSSION}

The results of this study showed that there is a positive impact of using internet in teaching TEFL especially on the students who feel more helped in their learning process which is consistent with Islam (2011) study that concentrated on the effect of internet that facilitates the improvement of the English level. However, the effect of internet on helping the teacher seems to be insignificant from the students' point of view as stated by Koivuniemi (2012) on his study.

As stated by the students, it was noted that the further explanation that the internet tools provide for students was the most common advantage of this method, while the simplicity of the internet tools was not considered as a positive feature. Moreover, openness, learning autonomy, stimulating interests of learners in language learning and strengthening learners' learning autonomy are some of the advantages of internet-based learning (Daneshdoust, 2012). However, lack of communication between students and teacher was the main disadvantage of using internet in TEFL courses.

According to Aydin (2007), prior studies showed that there are many disadvantages of using internet in second language learning. For instance, communication with native speakers influences reading skills badly. Moreover, writing and speaking skills. Though it is known that the internet enhances language and communicational skills, the important point is that learners and teachers are not aware sometimes of how, why, where and whom they learn and teach.

The results showed also that YouTube is the most effective internet-based way in teaching TEFL, while EduBuncee is the lowest one. This result is consistent with many studies including (Khalid \& Muhammad, 2012; Alhamami, 2013; Almurashi, 2016; Bastos \& Ramos, 2009; Kabooha \& Elyas, 2015).

\section{CONCLUSION}

This study was conducted to investigate about the effectiveness of internet-based learning in TEFL courses in Kuwait. The results showed that the effect was positive where this method helped the students in the learning process. moreover, the further explanation internet offer fir students was the most common advantage of internetbased learning while the lack of communication is the major disadvantage. Moreover, it was found that YouTube is the most common effective internet-based way in teaching TEFL.

\section{REFERENCES}

[1] Alhamami, M. (2013). Observation of YouTube language learning videos (YouTube LLVS). Teaching English with Technology, 13(3), 3-17.

[2] Almurashi, W. A. (2016). The Effective Use of Youtube Videos for Teaching English Language in Classrooms as Supplementary Material At Taibah University in Alula. International Journal of English Language and Linguistics Research, 4(3), 32-47. 
[3] Arsham, H. (2002). Impact of the Internet on Learning and Teaching. USDLA Journal, 16(3), 9-20

[4] Aydin, S. (2007). The use of the Internet in ESL learning: problems, advantages and disadvantages. Humanising language teaching, 9(1), 1-3.

[5] Bastos, A., \& Ramos, A. (2009). YouTube for learning English as a foreign language: critical thinking, communicative skills. In EDULEARN09 Conference (pp. 2087-2092). Iated.

[6] Crystal, D. (2012). English as a global language. Cambridge university press. London: Routledge

[7] Daneshdoust, B. (2012). The advantages and disadvantages of Internet-based language learning in Iran. Procedia-Social and Behavioral Sciences, 31, 607-611.

[8] Erben, T., Ban, R., \& Castaneda, M. (2008). Teaching English language learners through technology. New York: Routledge

[9] Graddol, D. (1997). The future of English. London: The he British Council, 7, 9-23

[10] Higgins, S., Xiao, Z., \& Katsipataki, M. (2012). The impact of digital technology on learning: A summary for the education endowment foundation. Durham, UK: Education Endowment Foundation and Durham University.

[11] Honna, N. (2005). English as a multicultural language in Asia and intercultural literacy. Intercultural Communication Studies, 14(2), 73-89

[12] Irmscher, J. A. (2011). Critical review of TEFL as an effective method of teaching English in a multi-cultural environment. (Master Thesis). Central university of technology

[13] Islam, M. N. (2011). Independent English Learning through the Internet. Journal of Language Teaching \& Research, 2(5), 1080-1085

[14] Kabooha, R., \& Elyas, T. (2015). The impacts of using YouTube videos on learning vocabulary in Saudi EFL classrooms. In ICERI 2015 Conference (pp. 3525-3531).

[15] Karisiddappa, C. R. (2002). Internet in the changing Educational Scenario. Paper presented at the ninth National Convention for Automation of libraries in education and research Institutes, CALIBER, Jaipur, Feb 14-16, 296-306.

[16] Khalid, A. Z., \& Muhammad, K. (2012). The use of YouTube in teaching English literature: the case of Al-Majma'ah Community College, Al-Majma'ah University (case study). International Journal of Linguistics, 4(4), 525.

[17] Koivuniemi, M. (2012). Learning English vocabulary using the Internet: a quantitative study of a group of first-year upper secondary students. University of Jyväskylä, Department of Languages

[18] McLaughlin, B. (1992). Myths and Misconceptions about Second Language Learning: What Every Teacher Needs to Unlearn. Educational Practice Report 5.

[19] Medina, M. (2002). A study of Hispanic EFL students learning English within a CALL classroom: Student introspection on learning, technology, and community (pp. 1-280). Indiana University of Pennsylvania.

[20] Motterram, G. (2013). Innovations in learning technologies for English language teaching. The British Council.

[21] Parvin, R. H., \& Salam, S. F. (2015). The Effectiveness of Using Technology in English Language Classrooms in Government Primary Schools in Bangladesh. In FIRE: Forum for International Research in Education (Vol. 2, No. 1, pp. 47-59). Lehigh University Library and Technology Services. 8A East Packer Avenue, Fairchild Martindale Library Room 514, Bethlehem, PA 18015.

[22] Patel, C. (2013). Use of multimedia technology in teaching and learning communication skill: An analysis. International Journal of Advancements in Research \& Technology, 2(7), 116-123.

[23] Pun, M. (2014). The use of multimedia technology in english language teaching: a global perspective. Crossing the Border: International Journal of Interdisciplinary Studies, 1(1), 29-38.

[24] Raiskinmäki, J. (2017). The use of technological devices in English teaching as experienced by teachers. (Bachelor's thesis). University of Jyväskylä.

[25] Robová, J. (2013). The impact of web sites on teaching and learning mathematics. Procedia-Social and Behavioral Sciences, 93, 631-635.

[26] Sawadogo, J. B. (2004). How EFL Teachers Can Organize the Use of the Target Language for Effective Classroom Interaction: The specific Case of Burkina Faso, With Special Reference to the English Oral Expression in 1èreA classes. Unpublished thesis. ENSK: Koudougou.

[27] Schwartz, B. L., \& Perfect, T. J. (2002). Introduction: Toward an applied metacognition. In T. J. Perfect \& B. L. Schwartz (Eds.), Applied metacognition, 1-11. Cambridge, UK: Cambridge University Press.

[28] Shyamlee, S. D., \& Phil, M. (2012). Use of technology in English language teaching and learning": an analysis. In International Conference on Language, Medias and Culture (Vol. 33, pp. 150-156).

[29] Ta'amneh, M. (2014). The Effect of Using Educational Websites on First Year Students' Achievement in English Grammar in Badr Community college. Journal of Emerging Trends in Educational Research and Policy Studies, 5(2), 184- 189

[30] Taylor, P. (2002). Global communications. International affairs and the media since 1945. London: Routledge.

[31] Toyoda, E. (2001). Exercise of learner autonomy in project-oriented CALL. Call-Ej Online, 2(2), 2-2.

[32] Wong, L. (2013). Student engagement with online resources and its impact on learning outcomes. In Proceedings of the Informing Science and Information Technology Education Conference (pp. 129-146). Informing Science Institute.

Amel Khalaf was born in Kuwait in 1968. She received her Masters of Science in TESOL from Florida International University in 1995.

She is currently an associate language teacher at the English Language Unit, College of Arts, Kuwait University. Her research interests include TESOL and the role of technology in second language acquisition.

Mrs. Amel Khalaf is a member of TESOL Kuwait and TESOL Arabia. 